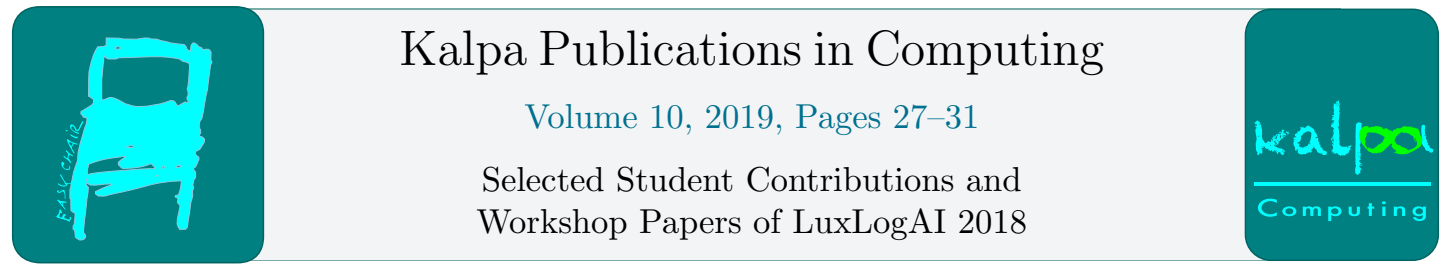

\title{
Leibniz on Reasoning about Impossible Concepts
}

\author{
Lukas Grätz \\ Institut für Philosophie, Universität Leipzig, Germany \\ lukas.graetz@studserv .uni-leipzig.de
}

\begin{abstract}
Leibniz wrote down a proof for the existence of God accompanied by a note on impossible concepts. A possibly true contradiction is quite unusual and not compatible with mainstream logic or his "Theodicy". His example of such a contradiction about an impossible concept, the "square circle", is still popular in contemporary metaphysics. Similar examples make the proposition of contradiction and possible truth controversial. An alternative formalization approach avoids contradictions by using a description logics extension to a different kind of concept composition.
\end{abstract}

\section{Proof of God's Existence and Leibniz's Note}

The Manuscript LH IV, 1, 13a, Bl. 3 (Gottfried Wilhelm Leibniz Bibliothek - Niedersächsische Landesbibliothek, Hannover) presents a proof of God's existence "if God is possible, God exists" on a single-sided paper. Below a rule there is also a note on impossible things. The manuscript was dated around January 1678 (see [7, N. 164] for a transcription).

See $[1,8,9]$ for formalization approaches for the proof. In my opinion, these do not cover all nuances in the Latin original.Leibniz's (semiformal) logic includes some interesting (obscure) aspects that are hardly accessible in modern logic. However, the main issue of my poster is Leibniz's example of an impossible concept:

Notandum hic est, quod conclusio implicans contradictionem potest esse vera, si scilicet sit de re impossibili. V.g. circulus quadratus non est circulus. Quae propositio vera est, etsi contradictoria sit, nam ex veris legitime probatur hoc modo: Quadratus non est circulus, circulus quadratus est quadratus, Ergo circulus quadratus non est circulus.

This can be translated into English:

Note that

A conclusion which includes a contradiction is possibly true, if the conclusion is on impossible concepts ${ }^{1}$.

E.g. A rectangular circle is not a circle.

This proposition is true despite being contradictory, since it is legitimately provable

${ }^{1}$ Latin: res impossibile other translations: impossible things, impossible objects

C. Benzmüller, X. Parent and A. Steen (eds.), LuxLogAI 2018 (Kalpa Publications in Computing, vol. 10), pp. $27-31$ 
in the following way:

A rectangle is not a circle.

A rectangular circle is a rectangle.

Hence a rectangular circle is not a circle.

\section{Contradiction and Paraconsistency?}

Leibniz apparently did not use Classical Logic, which was developed 200 years later. But what kind of logic has true contradictions $A \wedge \neg A$ ? In Classical logic and "Leibniz's Algebra of Concepts" such an "Impossible Thing" contains any property by ex contradictione quodlibet which is probably not intended. Today, there are paraconsistent logics allowing true contradictions.

\section{On the Back...}

Leibniz's manuscript is the back of a letter by Henning Huthmann. In the letter, he denials that you can proof God's existence. He was a remarkable person who will loose his job as a school principal due to a divergent opinion on justification (theology). He wrote a linguistic textbook[4] that was apparently never published. In "Cap. XV. Daß ein iedes Wort zu einem andern Worte gesetzt entweder eben dasselbe oder auch etwas anders abbilde" (pp 78-123) he used claims that in a sentence two words like "Caeci vident" (The blinds see) stand for the same group of people, although "the blinds" alone means something else, i.e. not "Etwas-Ebendasselbe" (pp 113-117). Huthmann apparently took this example from the latin bible.

This seems to be similar to the debate in modern linguistics on how to deal with phrases like "stone lion" and "fake gun" in formal semantics (see [12]), although "stone" and "lion" contradict each other.

\section{Impossible Numbers}

For Wittgenstein, the concept "number" was beside the concept "game" the main example to show that each of our definitions of such concepts fails: Our initial definition would not be wide enough and all that remains is a family resemblance between different types of numbers (c.f. [14]). However, in a knowledge base (of the mathematical domain), we would need to start with definitions to formalize concepts and individuals. Once the concept of a "number" is in the knowledge base, it would be really hard to alter the (TBox-)definitions, since there is a huge amount of data about individual numbers (in the ABox) that would need to be changed accordingly. So once we set "number" to match all the real numbers, it would be difficult integrate all complex numbers into the concept of a "number".

If we are looking in history, we notice that this corresponds to what happened (although the mathematicians didn't have knowledge bases). The time after complex numbers like $\sqrt{-1}$ were introduced, some mathematicians called them "complex number" but not "number" because these numbers were said to be impossible or imaginary [11]. Impossible means not making the ontological commitment of saying that $\sqrt{-1}$ exists in reality (c.f. [10]). It took some time until complex numbers got accepted to belong to the concept "number". This brings us back to Leibniz's example "rectangular circle", which Leibniz called contradictory and impossible. 


\section{Adjectives as Modal Operators in Description Logics}

The examples of "rectangular circle", "stone lion", "complex number" and finally "veggie burger" motivated me to develop a logic to deal with these concepts in knowledge representation formally. A "burger" is defined to contain meat, and although the concept "veggie burger" is in some sense equivalent to the "burger", there intersection is empty. As it turns out, "veggie" modifies the concept of a "burger": A veggie burger $x$ is a burger under a different perspective, different from the common sense viewpoint of the ABox where $x$ could be only called "veggie".

It turned out, that the adjectives mentioned behave like a modal operators. If you take this further, every predicate $P$ can be converted into a modal operator $\diamond_{P}$. However, classical logics does not talk about concepts like description logics or Leibniz's algebra of concepts. For this reason, I chose to extend description logics instead of classical logics. A similar approach was already used in [5]. To make it more readable, a binary operator $\multimap$ was used instead of $\diamond$ : This means, a "veggie burger" is translated into veggie $\multimap$ burger. See [3] for a closer look on the still tentative logic applied to the "veggie burger" knowledge base.

\subsection{Formalization by FOL Embedding}

$\mathcal{A L C}$ can be embedded into first order logic $(F O L)$ using a translation function $\pi_{x}: \mathcal{L}_{\mathcal{A L C}} \rightarrow$ $\mathcal{L}_{F O L}$, which converts $\mathcal{A L C}$ formulas into $F O L$ with one free variable $x$ (see $\left.[13,2]\right)^{2}$ Slightly modifying $\pi$ gives us the desired properties (for $C, D$ concepts, atomic concepts $A$ and viewpoints $v_{1}$ )

$$
\begin{aligned}
{ }^{v_{1}} \pi_{x}: \mathcal{L}_{\mathcal{A} \mathcal{L C}}^{-\circ} & \rightarrow \mathcal{L}_{F O L} \\
C \sqcup D & \mapsto{ }^{v_{1}} \pi_{x}(C) \vee{ }^{v_{1}} \pi_{x}(D) \\
\neg C & \mapsto \neg{ }^{v_{1}} \pi_{x}(C) \\
C \sqcap D & \mapsto{ }^{v_{1}} \pi_{x}(C) \wedge{ }^{v_{1}} \pi_{x}(D) \\
\forall r . C & \mapsto \forall y\left(p_{r}(x, y) \rightarrow{ }^{v_{1}} \pi_{y}(C)\right) \\
\exists r . C & \mapsto \exists y\left(p_{r}(x, y) \wedge{ }^{v_{1}} \pi_{y}(C)\right) \\
A & \mapsto \exists v_{2}\left(q_{A}\left(v_{1}, v_{2}\right) \wedge e\left(v_{2}, x\right)\right) \\
A \multimap D & \mapsto \exists v_{2}\left(q_{A}\left(v_{1}, v_{2}\right) \wedge e\left(v_{2}, x\right) \wedge{ }^{v_{2}} \pi_{x}(D)\right)
\end{aligned}
$$

where $q_{A}(\cdot, \cdot), p_{r}(\cdot, \cdot)$ and $e(\cdot, \cdot)$ are $F O L$-predicates. There are two main differences between this embedding and the classical embedding: First we have the extra viewpoint parameter $v_{1}$ and then the atomic concepts are not translated into unary predicates $A \mapsto q_{A}(x)$. In contrast to the classical embedding, concepts are translated into relations between viewpoints, e.g. a "fake gun" is "fake" in the designated, common sense viewpoint $v^{*}$ but a gun in the faker's viewpoint.

$e(v, x)$ denotes if an individual $x$ belongs to a viewpoint $v$. For example, we want to ensure that glass $\multimap$ gummy_bear $(x)$ exists in a glass and a glass $\multimap$ gummy_bear viewpoint by the shrinking domain assumption (2) for viewpoints $v_{1}, v_{2}$, atomic concepts $A$ and individuals $x$ :

$$
e\left(v_{2}, x\right) \wedge q_{A}\left(v_{1}, v_{2}\right) \rightarrow e\left(v_{1}, x\right)
$$

\footnotetext{
${ }^{2}$ For each transformation rule, two variants are needed for the permutations of the two variables $x$ and $y$. In the modified embedding presented here, the transformation rules for the permutations ${ }^{v_{2}} \pi_{x},{ }^{v_{1}} \pi_{y}$ and ${ }^{v_{2}} \pi_{y}$ can be defined likewise.
} 
The relation predicates for special concepts $q_{\top}$ and $q_{\perp}$ are defined as following:

$$
\begin{aligned}
& q_{\top}\left(v_{1}, v_{2}\right): \leftrightarrow v_{1}=v_{2} \\
& q_{\perp}\left(v_{1}, v_{2}\right): \leftrightarrow \text { False }
\end{aligned}
$$

\subsection{General Concepts}

The next step is to introduce some general concepts. Classical description logic already has the universal concept $T$ and the empty concept $\perp$. In the new extension, I found three other concepts that seem to make a lot of sense and provided them with symbols. First you want to distinguish a real gummy bear from a glass gummy bear, for example, and therefore we define "real" real $\multimap C \equiv C$ as a generalization concept. It turned out that $T$ is the suitable candidate for this, because $T \multimap C$ was simply not defined until then and $T \multimap C \equiv T$ would not be coherent with the two general generalization concepts below, which are quite plausibly.

The second generalization concept can be described as "in the broader sense". In a broader sense, gummy bears can be a glass gummy bear or a real gummy bear, because "in a broader sense $C$ " describes every object that is described by any generalization of $C$. Since the sense extends in all directions, I have chosen the spiral ๑ as a symbol for the concept "in the broader sense".

Finally the concept "false" marked with the symbol F is still missing, so a false gummy bear is certainly no gummy bear, however in the broader sense a gummy bear.

The classical modal operator "possible" $\diamond$ can also be formalized in this logic. For example, a "possible car" $\diamond \multimap$ car could be a car-like vehicle that we only see from distance and therefore cannot exactly identify. ${ }^{3}$ It could also be a bus, for example. The modal operator "necessary" $\square$ has no equivalent as a generalization concept. However, because of the modal logic equivalence $\square \equiv \neg \diamond \neg$, necessary $C$ corresponds to the concept $\neg(\diamond \multimap \neg C)$. (8) is equivalent to $\neg(\diamond \multimap \neg C) \sqsubseteq C$, which is similar to the modal logic axiom T.

Definition 5.1 (Useful Concepts). The following axioms should hold for every concept $C$ :

$$
\begin{aligned}
\top \multimap C & \equiv C \\
\text { ๑ } & =\bigsqcup_{D \text { Concept }} D \multimap C \\
\mathrm{~F} \multimap C & \equiv \neg C \sqcap \text { } \multimap C \\
C & \sqsubseteq \diamond \multimap C
\end{aligned}
$$

Note: (6) is defined as a union of all concepts $D$. This could be problematic, since this definition is circular.

\section{$6 \quad$ Results}

The DL extension is more expressive then basic DL, the "veggie burger" is a nice example. The scope of the approach is not yet determined. Although inspired by language, it has a clear semantics and no vagueness or ambiguity. This is a great advantage of logical formalism over natural language, if it is not the main goal to formalize natural language.

\footnotetext{
${ }^{3}$ Leibniz used a similar example: A square tower is mistaken to be round from distance (see [6], preliminary dissertation $\S 64$, essays $\S 32, \S 356)$.
} 
Leibniz did not explain why a "square circle" should be impossible or a contradiction. This becomes even more questionably in comparison to similar examples of conflicting compositions like "veggie burger" or "complex number" which seem(ed) to be impossible. It is controversial whether we should make the ontological commitment and postulate the existence of abstract objects like rectangular circles and complex numbers. Formalization of Impossible Concepts can be done with a description logics extension for concepts as modal operators.

\section{References}

[1] Bentert, M., Benzmüller, C., Streit, D., Paleo, B.W.: Analysis of an Ontological Proof Proposed by Leibniz. In: Charles, T. (ed.) Death and Anti Death, Vol. 14: Four Decades After Michael Polanyi, Three Centuries After G. W. Leibniz. RIA University Press (2016)

[2] Borgida, A.: On the relative expressiveness of description logics and predicate logics. Artificial Intelligence 82(1), 353 - 367 (1996)

[3] Grätz, L.: Concepts as modal operators in description logics. In: Ortiz, M., Schneider, T. (eds.) Proceedings of Description Logics (DL 2018). CEUR, vol. 2211 (2018), http://ceur-ws.org/ Vol-2211/paper-18.pdf

[4] [Huthmann], H.: [Gründliche Sprachkunst insonderheit auf das Latein eingerichtet] (ca 1690), http://diglib.hab.de/drucke/kg-360/start.htm, HAB Wolfenbüttel <M: Kg 360>

[5] Klarman, S.: Description logics for relative terminologies. In: Icard, T., Muskens, R. (eds.) Interfaces: Explorations in Logic, Language and Computation. pp. 124-141. Springer, Berlin, Heidelberg (2010)

[6] Leibniz, G.W.: Theodicy (Essais de Théodicée sur la bonté de Dieu, la liberté de l'homme et l'origine du mal). Open Court (1985), translated by E. M. Huggard

[7] Leibniz, G.W.: Sämtliche Schriften und Briefe, Reihe II, Band 1. Akademie Verlag (2006), https: //www.uni-muenster.de/Leibniz/bd_2_1_2009.html

[8] Lenzen, W.: Das System der Leibnizschen Logik. Walter de Gruyter (1990)

[9] Lenzen, W.: Leibniz's ontological proof of the existence of god and the problem of "impossible objects". Logica Universalis 11(1), 85-104 (Mar 2017). https://doi.org/10.1007/s11787-017-0159-2

[10] Linnebo, Ø.: Philosophy of Mathematics. Princeton University Press (2017)

[11] Nagel, E.: "impossible numbers": a chapter in the history of modern logic. In: Studies in the history of ideas, vol. 3, pp. 429-474. Columbia University Press (1935)

[12] Partee, B.H.: Privative adjectives: Subsective plus coercion. In: Presuppositions and Discourse: Essays Offered to Hans Kamp, pp. 273-285. Emerald Group Publishing (2010), https: //doi.org/ 10.1163/9789004253162_011

[13] Sattler, U., Calvanese, D., Molitor, R.: The Description Logic Handbook, chap. Relationships with other Formalisms. Cambridge University Press, second edn. (2007)

[14] Wittgenstein, L.: Philosophical investigations. Blackwell, Oxford, 4 edn. (2009), translated by G.E.M. Anscombe 